\title{
DOSSIÊE
}

Sociologias, Porto Alegre, ano 15, no 34, set./dez. 2013, p. 76-109

\section{Contar hoy la violencia de ayer: video y literatura actual sobre la transición política española}

\section{Resumen}

Proponemos un diálogo transdisciplinar entre el análisis sociológico de las representaciones y la interpretación crítica de prácticas estéticas (literatura y vídeo) para esbozar una mirada singular sobre la violencia social. En concreto, observaremos diversas prácticas estéticas contemporáneas que abordan la Transición Política española (1973-1985), construyendo discursos muy divergentes entre sí. Los discursos actuales sobre la Transición tienden a situarse entre dos posiciones extremas: una visión crítica y una visión celebratoria. Establecido esto, pasamos a comentar con más detalle algunas obras recientes que muestran una a visión crítica de la Transición. En concreto, observaremos dos novelas recientes de género policial, que sitúan su acción en los años de la Transición, y dos ejercicios de video-ensayo contemporáneo que impugnan la visión celebratoria, construida como el discurso dominante sobre la transición. Finalmente, evaluaremos la pertinencia de este tipo de abordaje transdisciplinar para indagar sobre debates en abierto que involucran el ejercicio de la violencia.

Palabras-clave: Transición política española. Literatura española. Práticas estéticas críticas. Violencia social.

\footnotetext{
*New York University, New York - NY, United States of America.

${ }^{* *}$ Universitat de València, València, España.
} 


\section{Telling today yesterday's violence: contemporary video and literature on Spain's political transition}

\section{Abstract}

We propose a transdiciplinary dialogue between the sociological analysis of representations and the critical interpretation of aesthetic practices (literature and video) in order to bring up a singular gaze on social violence. In particular, we take note of various contemporary aesthetic practices involving the theme of Spanish Political Transition (1973-1985), which build quite contrasting discourses. The current discourses on the Transition tend toward two extremely opposed positions: a critical view and a celebratory view. In the light of this, we comment in detail some recent works that present a critical perspective of the Transition. We take, in particular, two recent crime fiction novels that set their action in the years of the Transition, and also two contemporary video essays that challenge the celebratory view, the hegemonic discourse on the political transition. Finally, we evaluate the relevance of such kind of transdisciplinary approach for inquiring on the open debates involving the practice of violence.

Keywords: Spanish political transition. Spanish literature. Critical aesthetic practices. Social violence.

\section{Introducción metodológica: un diálogo transdisciplinar para acercarse a la violencia}

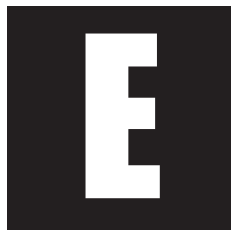

n este artículo partimos de una concepción de diálogo posible entre las ciencias sociales y las prácticas estéticas, entre el discurso científico y el discurso llamado humanista, entre la sociología, el arte y la literatura. El potencial que atribuimos a esta convergencia de discursos se sostiene en una posición epistemológica emergente e inestable que, desde la constatación de una crisis del paradigma racionalista y posi- 
tivista propio del siglo XIX (dominante durante todo el siglo XX), especula sobre las características del nuevo paradigma emergente. Con Boaventura de Sousa Santos, imaginamos en este paradigma emergente una epistemología que establece analogías y traducciones entre saberes y lenguajes (líneas de agua en lugar de compartimentos disciplinares estancos), que cuestiona la división sujeto/objeto desde el ejercicio de la reflexividad, en definitiva, un discurso científico que se aproxima cada vez más al discurso de la crítica literaria (Santos, 2009, p. 54).

Así, pese a que desde la sociología nos aproximaremos al discurso artístico y literario, esto no se hace estrictamente desde una sociología de la literatura, en el sentido que le podría atribuir la sociología del campo artístico de Bourdieu, donde el pensamiento científico parecería imponerse al objeto literario. Pensamos ahora, sin menoscabo de ese otro modelo, en una línea de trabajo que nos permita superar las fronteras disciplinares acercándonos al concepto de la estética del conocimiento postulado por Jacques Rancière (2008 y 2009, p. 281-282) o a la idea de transdisciplinariedad propuesta por Pollock (2007).

Partiremos de este marco de pensamiento para reflexionar sobre la representación y la memoria social de la violencia política de un proceso histórico concreto: la llamada Transición española. Por lo dicho hasta ahora, nuestra aproximación a este complejo tema se sitúa cercana a una Sociología de la Violencia y la Conflictividad, según la formulación de José Vicente Tavares dos Santos. Esta propuesta parte de unas ideas-elemento claves para este trabajo: la noción de complejidad, la historicidad de los procesos sociales, la perspectiva relacional de las relaciones sociales, y el privilegio de la contradicción en la antinomia regla/conflicto (Tavares dos Santos, 2009, p. 18). Siguiendo a este autor, abandonaremos una concepción soberana del poder, para observar la "violencia política", la ejercida principalmente por el Estado y contra el Estado, con una orientación y un 
significado que remite directamente a la organización del sistema social. Sin embargo, no nos limitaremos a un abordaje retrospectivo del proceso, sino que indagaremos especialmente sobre los discursos actuales construidos sobre este momento histórico.

El recurso a obras literarias y artísticas recientes se hace así especialmente pertinente. Este corpus nos permitirá analizar la construcción y enfrentamiento de imaginarios políticos y sociales al considerar los discursos textuales y visuales no ya como un producto pasivo del campo sociopolítiCo, sino como un elemento activamente implicado en la construcción del mismo (Mitchell, 2003, p. 34). Sin querer entrar en un debate que intente apurar la verdad última de la Transición, ni establecer juicios valorativos sobre "lo que se hizo" o "lo que se pudo hacer", lo que nos interesa en este estudio es cotejar las diferentes narrativas que permean los discursos sobre este proceso histórico, y establecer relaciones coherentes y articuladas entre los discursos de "lo real" (historia, sociología, ciencia política...) y los discursos de vocación estética o "ficcional" (literatura, cine, video-ensayo...) - asumiendo, con ello, una perspectiva cercana a lo que Rancière (2000) denomina la imbricación de la lógica de los hechos y la lógica ficcional.

\section{Algunas consideraciones sobre la Transición española} (1973-1983)

El proceso histórico conocido como Transición española señala el paso de la dictadura franquista a un sistema democrático de monarquía parlamentaria. En principio, todo estudio histórico de este proceso parte de la muerte del dictador Francisco Franco, el 20 de noviembre de 1975. Con todo, las diferentes cronologías y periodizaciones establecidas resaltan uno u otro hito en función de la faceta del proceso que se quiera abordar. Una cronología que atendiese estrictamente a los cam- 
bios en política institucional, señalaría acontecimientos como la aprobación por las Cortes Generales franquistas de la Ley para la Reforma Política (18/11/1976), la legalización y salida de la clandestinidad del Partido Comunista de España (09/04/1977), la ratificación en referéndum de la nueva Constitución (06/12/1978), o finalmente, la victorial electoral del Partido Socialista Obrero Español (PSOE), que llevó a la presidencia del gobierno a Felipe González (28/10/1982). Sin embargo, una cronología que abordase la persistente violencia política del proceso, señalaría como fundamentales otros acontecimientos: el asesinato del almirante Carrero Blanco, delfín de Franco, en atentado del grupo terrorista ETA (20/12/1973), la ejecución de cinco militantes de ETA y GRAPO, con las últimas sentencias de muerte firmadas por el dictador (27/09/1975), la matanza de los abogados laboralistas de Atocha por un comando de ultraderecha (24/01/1977), el intento fallido de golpe de estado orquestado por mandos militares (23/02/1981), o los primeros crímenes del GAL, ya bajo gobierno socialista, tomando el relevo en la guerra sucia contra el terrorismo (diciembre de 1983). Como se puede imaginar, el retrato que obtenemos de este proceso, si atenemos a una u otra cronología, es muy diferente.

Como señala Mariano Sánchez Soler (2010), la mayoría de análisis publicados sobre la Transición se centran en los pactos en las alturas y el acuerdo entre políticos con visión de futuro constituyendo, en definitiva, una amplia bibliografía de textos hagiográficos sobre líderes clarividentes llevando a cabo un proceso político modélico y pacífico. Podrían citarse innumerables ejemplos en este sentido, no sólo desde el estudio histórico o la ciencia política, sino también desde la crónica periodística o la literatura. Una obra paradigmática en este sentido sería la serie documental La Transición de Elías Andrés y Victoria Prego emitida por Televisión Española entre julio y octubre de 1995. Esta serie propone un relato que, si bien refiere puntualmente algunos episodios de violencia política que caracterizaron 
este proceso ${ }^{1}$, centra su atención en las decisiones de líderes como Adolfo Suárez, Santiago Carrillo y, muy especialmente, Juan Carlos de Borbón, cuyos pactos intra-élite habrían conducido linealmente a las elecciones de junio de 1977 y la constitución de las primeras cortes democráticas. Otros ejemplos en esta misma línea desplazan el punto culminante del proceso transicional al golpe de estado fallido del 23 de febrero de 1981, donde la intervención de estas figuras, con el papel central del rey Juan Carlos, explicaría la resolución pacífica y democrática de los hechos ${ }^{2}$. Lo que nos interesa retener de esta genealogía de relatos y representaciones históricas es el modo en que escamotean o atribuyen un peso mínimo a la movilización de centenares de miles de ciudadanos luchando por sus derechos, frente a la que el Estado desplegó una violencia sistemática, así como al complejo entramado de violencia política - estatal, para-estatal y contra-estatal que caracterizó este proceso (Sánchez Soler, 2010, p. 15).

La explicación del silenciamiento de la intensa violencia que caracterizó la Transición se ha visto lastrada por un buen número de tópicos y automatismos críticos. Con Jo Labanyi (2011) podemos identificar en el cliché del desencanto un ejemplo central de ello. Este término ha sido utilizado con insistencia para referirse al estado de ánimo que marcó el proceso político transicional. En su empleo jugó un papel clave la recepción crítica del documental homónimo de Jaime Chávarri (1976). En El desencanto, el director entrevista a la viuda e hijos del difunto Leopoldo Panero, poeta oficial del franquismo, subrayando en éstos un estado aní-

\footnotetext{
${ }^{1}$ Sin duda no compartimos la lectura entusiasta de dicha representación tal y como se puede encontrar, por ejemplo, en Vilarós (1998, p. 132-135) quien celebra hiperbólicamente el trabajo de Prego como una lúcida representación crítica de la violencia de la Transición. Retomamos la crítica del trabajo de Vilarós más adelante.

${ }^{2}$ Más adelante comentamos con detalle la miniserie de televisión El día más difícil de El Rey (2009) y la novela de Javier Cercas Anatomía de un instante (2006) así como el documental de Andrés y Prego (1995).
} 
mico pinzado entre la pérdida de una figura opresiva y el conato de una catarsis liberadora que no llega a materializarse. De acuerdo con Labanyi, las lecturas formuladas desde el paradigma psicoanalítico dominante en los departamentos de literatura anglosajones en los 90 convirtieron la película de Chávarri en el emblema de una metáfora edípica en que la familia Panero representaría el sentir general de un estado español paralizado tras la muerte del Padre. Es el caso de Teresa Vilarós en su conocida crítica cultural de la Transición, El mono del desencanto, donde el término "mono" alude a la jerga con que los toxicómanos se refieren al síndrome de abstinencia. Con este tropo, Vilarós pretende complejizar la visión de la Transición como frustración, entendiendo el franquismo no sólo como un sistema político autónomo, sino como una enorme configuración social por la que el cuerpo social español habría desarrollado una mórbida adicción-y la incapacidad de su superación. El final del franquismo, al desarrollarse como muerte gestionada desde el poder y no como catarsis, habría hecho que la ausencia del dictador se viva como duelo y abstinencia, pero no como liberación transformadora, generando una suerte de pacto amnésico y desactivación crítica colectiva ${ }^{3}$.

Más allá de la problemática proyección de un vocabulario psicoanalítico sobre procesos históricos y sociales ${ }^{4}$, Labanyi alerta de que este tópico desatiende los usos y sentidos del término "desencanto" en los mismos años en que se desarrolló el proceso. Basándose en el trabajo de

\footnotetext{
${ }^{3}$ Entre otras derivaciones analíticas, esta premisa lleva a la autora a reflexionar muy seriamente sobre la irónica frase acuñada con sorna por Manuel Vázquez Montalbán, sobre el desánimo por la desintegración del antifranquismo a la muerte del dictador: Contra franco vivíamos mejor (Vilarós, 1998, p. 60-84)

${ }^{4}$ El caso de Vilarós no está aislado. Labanyi (2011, p. 80-3) cita otros trabajos posteriores que han seguido una línea similar, como el de Medina (2001), quien entiende la Transición como una incapacidad melancólica de enfrentarse con el propio pasado o el de Moreiras (2002), donde la supuesta imposibilidad de representar la dictadura franquista se asimila al concepto de trauma. Como complemento de la crítica de la metaforización psíquica del espacio cultural y social, cf. el trabajo de Jacqueline Rose (1988).
} 
Egea (2004), Labanyi recuerda que este término era omnipresente en la prensa de la época, especialmente desde las páginas de opinión de El País, entendido como portavoz del PSOE. El empleo del mismo, de hecho, tenía mucho que ver con la conveniencia, para los políticos del momento, de tener un público pasivo, que no pidiera cambios demasiado radicales (Labanyi, 2011, p. 81).

El argumento de Egea y Labanyi no parece alejado del desarrollado por el sociólogo Jesús Ibáñez en su artículo, redactado en plena Transición, La realidad como desencanto (1997 [1980]), en el que contrasta la etimología del término en la prensa de la época con las opiniones formuladas en un grupo de discusión realizado con obreros de la zona norte de Madrid. Muy crítico con los límites de la democracia formal representati$v^{5}{ }^{5}$, Ibáñez se basa en un esquema dialéctico entre lo real y lo imaginario, observando cómo en la transición a la democracia se realizó un tránsito indiscutido hacia el capitalismo de consumo mientras se aireaba el fantasma de un supuesto desencanto que llena todas las bocas y gotea-aquí y ahora-de todas las plumas (Ibáñez, 1997, p. 174). La línea argumental de su artículo se desdobla a partir de un sugerente juego semántico: El país está muy desencantado / ¿quién lo desencantará? / el (desdes)encantador que lo (desdes)encante / ibuen encantador será! (Ibáñez, 1997, p. 174-188), con el que sugiere que "el buen encantador" aprovecha en beneficio propio la capacidad de deshacer el desencanto. Este desencanto aparece con un nuevo sistema sociopolítico (el par democracia formal/ capitalismo de mercado) que se impuso con la aceptación connivente de la izquierda parlamentaria, destruyendo, por tanto, la identidad de resistencia construida en el periodo anterior (antifranquista) sin que un nuevo proyecto colectivo pudiera ocupar este vacío ideológico. Como remarca

\footnotetext{
${ }^{5}$ Ver los artículos políticos del periodo, compilados en el libro A contracorriente (1997). Destaca, por ejemplo, el artículo Posibilidades y límites de la democracia formal representativa (lbáñez, 1997, p. 61-80).
} 
Ibáñez: un sistema que permite la adherencia efectiva, pero no la adhesión afectada, es la definición misma del desencanto (Ibáñez, 1997, p. 182). Sin embargo, el ciclo del desencanto pareció anunciar su fin con la creciente "capacidad de encantamiento" del PSOE. La actuación del "encantador" Felipe González durante el debate de moción de censura contra Suárez se presenta como la única brecha en la continuidad del proceso abierta desde la oposición (Ibáñez, 1997 p. 186), y de alguna manera conseguiría "(desdes)encantar" al electorado, sin la necesidad de asentar un proyecto político alternativo en las bases de lo real. Ibáñez, consciente de que un poder es más estable cuanto más rígidamente están distribuidos lo real y lo imaginario, comprende la imposición de esta alternativa imaginaria como complemento del capitalismo de consumo, para que, ocupado cada uno en modelar su paraíso en la materia de los sueños, no intentemos excavar entre todos en la realidad un paraíso colectivo (Ibáñez, 1997, p. 187) ${ }^{6}$.

Desde este punto de vista, asimilar el tópico del desencanto como una suerte de espíritu de los tiempos que explicaría un estado de ánimo social generalizado parece más bien una imprecisión histórica en la que una categoría políticamente construida al servicio de unos intereses concretos (mirándolo bien, las masas no están desencantadas, están desencantados los—aspirantes a—encantadores diría Ibáñez, 1997, p. 182) deviene, acríticamente, una metáfora maestra para explicar la Transición en conjunto. Resulta evidente que la visión oficial desproblematizadora y que alababa la transición pacífica hacia la democracia como un modelo impecable y exportable, por su ejemplaridad, para países latinoameri-

\footnotetext{
${ }^{6}$ Con otro razonamiento, a esta misma conclusión llega Javier Cercas en Anatomía de un instante, donde afirma que el PSOE asumió por sorpresa el liderazgo de la izquierda porque supo absorber la cautela y el desencanto de muchos simpatizantes comunistas y también porque ofrecía una imagen de juventud y modernidad frente a los envejecidos candidatos del PCE (Cercas, 2009) De esta forma, entendiendo el inicio del gobierno del PSOE como desenlace de la transición, parece afirmarse el fin del desencanto y la celebración de una nueva España, democrática y pacífica, capitalista y europea.
} 
canos y postsoviéticos (una narrativa que calificaremos de celebratoria) nunca dejó de ser impugnada por todo un conjunto de posicionamientos políticos que denunciaron el continuismo de los aparatos de estado franquistas y la brutal violencia política que caracterizó el proceso (una

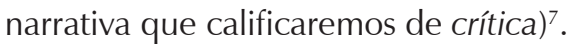

La violencia política y el desarrollo hegemónico de la Transición fueron cuestiones que no pasaron desapercibidas para la producción cinematográfica de los años setenta en el estado español. Se señala frecuentemente la representación del terrorismo y la violencia política en la trilogía de Gutiérrez Aragón-Camada negra (1977), Sonámbulos (1978) y El corazón del bosque (1979)—un caso al que podríamos añadir películas realizadas con un lenguaje cinematográfico más convencional—como, por ejemplo, Siete días de enero de Juan Antonio Bardem (1979). Al respecto, se suele recordar que estas películas eran una rareza minoritaria si se toma en consideración el conjunto de la producción cinematográfica del momento. Así analiza estos ejemplos Vilarós (1998, p. 135-151) citando frecuentemente la Historia del cine editada por Gubern quien a su vez ahonda en el tópico del pacto de silencio de la Transición al sugerir que sólo en contadas producciones cinematográficas se abordó frontalmente el complejo presente de aquellos días (Gubern, 1995, p. 382). Cabría observar, al respecto, el modo en que tanto la obra de Gubern como el resto de historias canónicas del cine español (p.ej. Monterde, 1993) excluyen tajantemente un amplio abanico de cine activista realizado y distribuido

\footnotetext{
${ }^{7}$ Desde este punto de vista, el tópico de la amnesia y la incapacidad de asimilar la situación política del presente - el abrumador silencio del que habla Vilarós (1998, p. 138) - se revela como un tópico insostenible. El reexamen histórico de las políticas de la memoria de la Transición muestra, de hecho, paradojas imprescindibles para situar a los diferentes agentes políticos en la órbita del discurso celebratorio o crítico-por volver al texto de Ibáñez, véase esta anécdota: el apresurado repudio [por el PCE y el PSOE] de los símbolos republicanos, produce la paradoja de que, en ocasiones, sus militantes persiguen la bandera tricolor con más saña que las 'fuerzas del orden' (1997, p. 179).
} 
al margen de la industria a través del cual se vehicularon preferentemente las críticas más articuladas contra el desarrollo hegemónico de la Transición (Soler de los Mártires y Romaguera i Ramió, 2006). Después de 1975 no sólo continuaron su actividad los colectivos de cine clandestinos ya activos los últimos años del franquismo-p.ej. Comisión de Cine de Barcelona y Colectivo de Cine de Madrid — sino que se asistió, en diferentes puntos del estado, al desarrollo de nuevas experiencias cinematográficas colectivas que no sólo dieron voz a un amplio espectro de movimientos sociales-autonomía obrera (Colectivo de Cine de Clase: $O$ todos o ninguno, 1975-6), movimiento vecinal (Vídeo-Nou: Història urbanística, 1978), insumisión y antimilitarismo (Cooperativa de Cinema Alternatiu: Can Serra: la objeción de conciencia en España, 1976), emancipación femenina (Cooperativa de Cinema Alternatiu: La Dona, 1976) y homosexual (J.R. Ahumada: Gais al carrer, 1977), etc.—sino también a la denuncia explícita de la violencia de Estado y su ocultamiento en los discursos oficiales (Colectivo de Cine de Madrid: Vitoria, 1976). Estudios recientes (García-Merás, 2007; Berzosa Camacho, 2009 y 2011) han abierto el camino para revalorizar y estudiar con atención este corpus marginalizado en los discursos académicos dominantes cuyas prácticas-desde la concepción estética de las películas, hasta la asimilación de los debates internacionales de los años 60-70 sobre el documental político pasando por la reinvención radical de los modos de producción, difusión y proyección cinematográfica—sin duda arrojarían luz sobre la representación de los discursos políticos más contestatarios de la Transición.

Otro género, en este caso literario, en el que la crítica política y social al statu quo de la Transición encontró un terreno fértil, fue la novela negra o policial. Este género experimentó un notable auge desde 1975 (Balibrea, 2002) por diversos factores de naturaleza socio-política, ideológica, estético-cultural, o comercial (Valles, 1988, p. 232-233). Entre estos, 
podríamos citar desde el fin de la censura que cortaba las alas a todo realismo, hasta la expansión de una industria editorial ávida de productos que pudiesen atraer tanto a lectores instruidos y exigentes como a los que buscaban simple entretenimiento. La dimensión crítica de la novela negra no se sostiene solo en el realismo:

La naturaleza eminentemente social de narradores como Manuel Vázquez Montalbán, Juan Madrid, Andreu Martí, Maria Antònia Oliver, Alfonso Grosso, Francisco González Ledesma o Jorge Martínez Reverte, parte, naturalmente, de la elección de sus temas, pero también de la estructura indagatoria en que se sustentan sus tramas. (Balibrea, 2002, p. 117)

Esta estructura indagatoria, característica del episteme de la modernidad y la estructura estatal burocrática, parece especialmente adecuada para interrogar los puntos negros de ese mismo Estado. La experiencia lectora, así, compagina la fruición del desvelamiento del misterio (la ilusión de iluminar tramas ocultas de lo real), con una estructura narrativa repleta de acción, abierta al mercado masivo. Como argumenta Balibrea (2002, p. 117), ante el pacto de silencio sobre el pasado de los que detentan el poder y sobre los mecanismos que utilizan para mantenerlo, hay mucho espacio para una utilización crítica e inconformista de la estructura indagatoria de la novela detectivesca. La novela negra podría alinearse así, tal y como lo hicieron muchos de los autores antes citados, con una perspectiva histórica crítica, que resalta las continuidades del sistema democrático con el régimen franquista, especialmente en lo que respecta a la violencia política.

Con todo, no es nuestro objetivo detenernos mucho más en las producciones cinematográficas y literarias de la época, sino interrogar cómo este proceso histórico ha sido abordado por las prácticas culturales contemporáneas. Al respecto, nos parece relevante dejar constancia de un renovado interés por este momento histórico en un momento en que, como consecuencia de la crisis económica, la estructura institucional del estado 
español vive un serio desgaste social y un cuestionamiento abierto de su legitimidad. Tratando de adoptar una visión de conjunto, podemos afirmar que en la actualidad se han reactivado_-si es que alguna vez llegaron a extinguirse por completo—las dos grandes narraciones previamente referidas (celebratoria y crítica). Sin ánimo de exhaustividad, ambas pueden ser eficazmente identificadas a través de su difusión en el ámbito periodístico.

La visión celebratoria, que insiste en entender la Transición como un proceso modélico y ejemplar que logró la inesperada construcción pacífica de una democracia, desmantelando completamente el sistema político autoritario de la dictadura franquista a través del espíritu de consenso y la responsabilidad histórica de los líderes, es frecuentemente evocada como proyecto político para el presente. La resolución de la actual crisis a través de la firma de grandes pactos de estado- una idea constantemente relacionada con la recuperación del espíritu de la Transición — viene siendo un eje fundamental del posicionamiento del diario El País, tanto en sus editoriales ${ }^{8}$ como en las firmas invitadas a sus principales espacios de opinión ${ }^{9}$.

Contrariamente, pervive una visión crítica que insiste en denunciar la Transición como un acuerdo de mínimos, con reformas "cosméticas" motivadas por el entorno político internacional (auge de las democracias parlamentarias y mercado capitalista), sin que se alterase en lo fundamental el sistema de poder establecido por las oligarquías franquistas. La dimensión "pacífica" de la Transición también es radicalmente puesta en cuestión, destacando no sólo los centenares de víctimas de la violencia política del periodo, sino también la constante amenaza de represión militar generalizada. Para el presente, esta visión afirma que sólo la revisión radical de la historia puede dar la vuelta a un sistema políticosocial

\footnotetext{
${ }_{8}^{8}$ Por ejemplo: Pactos de Estado (12 abril 2012), La foto de un consenso (26 julio 2012), o La urgencia de pactar (29 julio 2012).

${ }^{9}$ Por ejemplo: Sevilla y Piqué (2012), Marañón y Toharia (2012), Llera (2012).
} 
neofranquista. Contrarrestando el ejemplo anterior, puede citarse la línea editorial del medio digital eldiario.es, cuyo primer cuaderno monográfico en papel Ilevaba por título El fin de la España de la Transición. En el artículo de cabecera, Ignacio Escolar escribe: El mito fundacional [de la Transición] es falso por dos razones: porque hubo violencia, y mucha (...). Y porque lo verdaderamente inusual habría sido que España hubiese continuado siendo por mucho más tiempo una dictadura, la única de su tiempo en toda Europa occidental (Escolar, 2013, n.p.).

Las prácticas culturales contemporáneas (del 2000 en adelante) no son ajenas a la reactivación de estos debates, confirmando la idea de que, casi treinta años después, esta historia parece haber cerrado en falso generando la sospecha de que muchos de los misterios del presente tienen una respuesta—que nos pasó a todos desapercibida—en los años de la Transición. Desde la crítica cultural, pensamos, por ejemplo, en el trabajo del periodista Guillem Martínez (2012) sobre la llamada Cultura de la Transición, una configuración cultural forjada en este periodo presentada como un "límite de lo pensable", a la que se atribuyen todas las limitaciones del actual sistema democrático español. El libro de Mariano Sánchez Soler previamente referido, La transición sangrienta (2010), surge de la vocación explícita de contestar la versión oficial que presenta la Transición como un proceso pacífico, limpio y aséptico. Con su minucioso trabajo de investigación histórica, abundante en cifras, nombres y apellidos (de víctimas y verdugos), Sánchez Soler reivindica la memoria de las víctimas de esta violencia política, pues, como escribe, su olvido equivaldría a una segunda muerte. Por otro lado, Manuel Palacio destaca y critica las polémicas sectarias que convoca la Transición (entre los que la consideran fallida y los que reivindican sus logros), y se desmarca de lecturas presentistas del proceso que observan el pasado a partir de las necesidades y de los postulados que se tienen en la contemporaneidad (Palacio, 2011, p. 19). 
Entre la producción literaria y cinematográfica reciente, tampoco faltan las obras que insisten en la visión celebratoria. Entre ellas, podemos destacar de nuevo una producción de TVE, la mini-serie 23-F, el día más difícil del Rey, emitida el 10 y 12 de febrero de 2009 con gran éxito de audiencia. En ella se nos presenta, de forma extremadamente heroica, la versión oficial del fallido golpe de estado. Como el título indica, el protagonista del relato es el monarca, que con su eficaz reacción frenó el golpe y restauró el orden constitucional, perpetuando la todavía inestable democracia. Una versión algo más compleja, aunque convergente en lo esencial, la encontramos en la novela Anatomía de un instante, de Javier Cercas (2009). Técnicamente brillante desde el planteamiento a su ejecución, el minucioso trabajo de Cercas analiza lo ocurrido aquel 23 de febrero de 1981, moviéndose entre la novela de espías y la crónica periodística, hilvanando las biografías de los protagonistas (Suárez, Gutiérrez Mellado, Carrillo, Tejero, Armada...) con el contexto político de la transición. A la hora de establecer juicios de valor, Cercas no se pierde en medias tintas: En fin, el franquismo fue una mala historia, pero el final de aquella historia no ha sido malo. (...) Pudo haberlo sido, pero no lo fue, y no veo ninguna razón para que quienes por edad no intervinimos en aquella historia no debamos celebrarlo (Cercas, 2009). Esta narrativa de la transición reincide en las intrigas "de despachos" y los "pactos de altura" a las que hacía alusión Sánchez Soler, sin que aparezca otro personaje movilizado fuera del Congreso o la Zarzuela que el propio Cercas, en un prólogo en el que presenta su experiencia particular del golpe. Esta es la única referencia que se hace a un ciudadano deambulando por las calles, (auto)irónicamente presentado como un joven desorientado, sin demasiada convicción ni entusiasmo.

Más allá de estos relatos que actualizan la visión celebratoria, identificamos una serie de narrativas que, alineándose con la visión crítica del 
proceso, proponen un punto de ruptura de los consensos de la Transición y un esfuerzo por interrogar su representación hegemónica. Sobre algunas de estas obras detendremos la mirada.

\section{La visión crítica de la transición española en la cultura contemporánea}

Como comentamos antes, tanto la novela negra como la producción cinematográfica realizada desde diversos colectivos de cine tuvieron papel destacado en la transición, sirviendo de soporte para indagar el lado oscuro del proceso de transformación que se vivía en el país. Destacaremos algunas obras que, haciendo uso de estos géneros y conectando con la tradición de la transición, lanzan desde el presente una mirada instigante a ese periodo.

\subsection{Piel de Policía (Andreu Martín y Carles Quílez, 2006)}

La novela Piel de policía nos sitúa en torno de 1984, durante la formación de los Grupos Antiterroristas de Liberación (GAL), grupo terrorista parapolicial que ejerció la guerra sucia contra la banda vasca Euskadi Ta Askatasuna (ETA). El grupo organizado para el ejercicio del terrorismo de Estado tomó el relevo de muchos otros grupos similares (Triple A, Batallón Vasco-Español, Guerrilleros de Cristo Rey...) que desde los inicios de la transición actuaron con el apoyo o la connivencia de los diferentes gobiernos (Sánchez Soler, 2010).

La novela se centra en la rama barcelonesa del GAL, que se organiza en el seno del grupo Omega (división policial Antiatracos) especialmente activa en esos años. De esta forma, la novela arranca con la lucha estatal contra la violencia difusa (Tavares dos Santos, 2004), mostrándonos la brutal cotidianeidad de la policía antiatracos en un momento de elevada crimi- 
nalidad, en el que se llegaron a registrar más de 3000 atracos a bancos en un año. En la novela, el narrador recalca la relación entre esta elevada criminalidad y la reforma de la Ley de Enjuiciamiento Criminal (1983) llevada a cabo por el Ministro de Justicia Fernando Ledesma (PSOE). Al reducir la discrecionalidad de la prisión provisional, casi 9.000 presos [fueron] excarcelados prácticamente de una tacada por la 'reforma Ledesma' (Duva, 1994), generando un importante debate político. A esto debemos añadir la importante crisis económica marcada por un fuerte desempleo, que contribuiría al incremento de la inseguridad ciudadana (Hurtado, 1999, p. 99111). En este contexto, la novela nos muestra escenas de brutalidad policial que se asumen con naturalidad por los protagonistas: torturas normalizadas en los interrogatorios, impunidad de los abusos a los detenidos, ejecuciones extra-oficiales de delincuentes que quedan sin investigar...

A partir de esta caracterización de una policía "autoritaria", típica de regímenes totalitarios (Tavares dos Santos, 2009, p. 92), se construye un protagonista que rechaza y se enfrenta a este modelo. El inspector Lacruz se nos presenta como un joven de talante democrático que, a pesar de convivir con la violencia autoritaria, aspira a modernizar la policía. Éste narra en pasado los hechos de los años ochenta, desde un presente distante impreciso (próximo al momento de redacción de la novela, el 2006), pero también desde una marcada distancia moral.

En el presente de la narración, Lacruz ha dejado la policía y arrastra una existencia miserable. El acontecimiento misterioso que provoca esta ruptura es el centro del enigma que hace avanzar la novela. La construcción de Lacruz se realiza en relación a dos polos, representados por dos personajes principales: el inspector Castán, jefe del grupo Antiatracos, y Nuria, novia del protagonista. El inspector Castán será el enlace del grupo Omega con los GAL, que Lacruz irá investigando a lo largo de la novela con pericia detectivesca, descubriendo al lector algunos de sus atentados en Francia 
y el País Vasco, e iluminando sus conexiones con empresarios y partidos políticos de extrema derecha (por ejemplo, Fuerza Nueva). Por otro lado, Nuria, estudiante de Derecho y conocedora de la alta cultura, representa la burguesía catalana acomodada, de aspiraciones cosmopolitas y modernizadoras. Sobre la doble temporalidad de la narración, el desenlace de la novela resuelve el clímax con dos revelaciones: una brutal en los años ochenta, y una redentora en los dos mil. La primera es la violación de Nuria por Castán y sus secuaces, como represalia a Lacruz por su impertinente investigación desvelando las tramas ocultas del terrorismo de Estado, lo que provocará la renuncia de Lacruz a la carrera policial. La segunda, veinte años después, nos muestra a Nuria como juez, absolviendo a Lacruz por el asesinato de Castán, aun a sabiendas de su autoría del crimen vengativo.

En esta novela se combinan con gran solvencia las características mencionadas por Balibrea (2002): la fruición por la resolución de un enigma y el dinamismo de las acción, y el realismo documentado y crítico cercano a la crónica social. Tal vez para el éxito de esta empresa haya contribuido la complementariedad de perfiles de los coautores, en su segunda colaboración. Andreu Martín (1949), escritor consolidado con más de 30 novelas publicadas desde los años ochenta, es considerado uno de los maestros del género policial o de terror urbano (Balibrea, 2002; Colmeiro, 1994; Valles, 1988). Carles Quílez (1966), además de escritor fue periodista radiofónico para Tribunales y Policía, experiencia que contribuye para la construcción documental de la novela.

Sobre el retrato de la violencia política de la transición implícito en esta novela, nos parece que, entre las posiciones planteadas (celebratoria y crítica), esta novela se sitúa en la ambigüedad. De un lado, podríamos evaluar que la división temporal de lo narrado, y en especial el desenlace redentor, acentúan la visión de ruptura entre los dos regímenes políticos, el fascista y el democrático, personificados en dos generaciones de policí- 
as. Sin embargo, esta transición se daría de forma lenta, compleja y costosa, lastrada por continuidades no resueltas por las modificaciones legislativas. La relación entre las dos generaciones de policías muestra un dominio del tipo autoritario en los ochenta, que se habría ido disolviendo en el elipsis temporal de la novela, hasta invertirse en el presente de la narración. Es especialmente elocuente el pasaje en el que "el Niño", uno de los policías jóvenes en 1984, entra de improviso en la sala donde los veteranos están torturando a un detenido y, sorprendido, exclama: iEh, eh, que ya no se puede...!. Esta reacción provoca las carcajadas de los veteranos, que después de la paliza, comentan en el bar como resolvieron la situación tranquilizando a "el Niño": No te preocupes, que mañana el juez de guardia es un colega... Ante la tensión de la escena, la voz narrativa de Lacruz, parece resignarse con amarga ironía ante la ingenuidad de "el Niño":

O sea, hasta hacía poco cualquiera de nosotros podía retorcer los huevos a cualquier menda hasta arrancárselos de cuajo, era de buen tono, incluso aconsejable y plausible, incluso quedaba feo no hacerlo. Pero ahora no, que nos había llegado la democracia, ahora todo lo contrario. «Eh, eh, que ya no se puede.»Pero bueno, qué gracioso, pero qué gracioso (Martín; Quílez, 2011, p. 56).

Lo relevante en este retrato de la violencia política en transición de regímenes políticos es la dimensión moral del conflicto, que en la novela se resuelve en el plano individual. Lacruz, como arquetipo del investigador solitario contra viento y marea, paga los platos rotos de la transformación colectiva. Esta individualización de la responsabilidad, sea para la alabanza o para la condena, nos recuerda a la retórica oficial con la que las autoridades españolas se refirieron a grupos como el GAL: se trató siempre de grupos incontrolados, o acciones aisladas de individuos no adscritos, pese al claro origen institucional de esta violencia selectiva (Sánchez Soler, 2010, p. 356-360). Visto así, es importante recordar 
la discusión gramatical de Ibáñez en el artículo La policía y los policías (1997, p. 209-212): ¿Cuándo se puede decir que la policía ha hecho tal cosa, y cuándo se debe decir que un/os policía/s ha/n hecho tal otra? La pregunta, que Ibáñez deja en abierto, nos impide olvidar el uso político de la gramática, que puede marcar la diferencia entre una acción aislada imputada a un individuo incontrolado o la práctica generalizada de la violencia institucional.

\subsection{El jardín colgante (Javier Calvo, 2012)}

Esta novela narra la relación tensa entre el Servicio Secreto español (el CESID, creado en 1977 como fusión y reestructuración de la inteligencia militar franquista) y un ficticio grupo terrorista de inspiración maoísta (el TOD, vagamente inspirado en las FRAP, como un grupo de militantes comunistas descontentos con la política de "reconciliación nacional" defendida por el Partido Comunista Español). A pesar del obvio enfrentamiento, con atentados, espionajes y persecuciones, la trama plantea un trasfondo conspiratorio simétrico, de comunicación y complementariedad sistémica, en el que cada lado necesita del otro para perpetuarse. Así, el Servicio Secreto estaría tutelando un proceso de transición y rediseño institucional que permitiría controlar los límites del cambio.

Calvo se aparta del realismo documental más crudo, típico de la novela negra, para poner en juego una serie de símbolos, claves literarias y metáforas ambiguas. Los propios personajes adquieren este tinte caricaturesco: desde la triste pareja de investigadores del CESID, Aristides Lao (una mente autista y calculadora encerrada en un repulsivo obeso halopécico) y Melitón Muria (un gañán debatiéndose entre el tosco patriotismo y la vanidad ridícula), hasta el espía infiltrado en el TOD, Teo Barbosa (irritantemente sarcástico, corrosivo, burlándose de todo y de todos hasta que resulta difícil definir donde está su lealtad). El diálogo mudo entre los 
investigadores y el espía infiltrado (a base de rastros, mensajes ocultos, persecuciones e intuiciones) hace avanzar la acción hacia el encuentro final. Esta búsqueda se desarrolla en dos partes. La primera nos muestra una Barcelona en tinieblas, adormecida entre las brumas dejadas por un meteorito, y deslumbrada por fulgurante mito de la Nueva España. La segunda se centra en el islote en el que se oculta el comando terrorista tras el atentado, creando una suerte de sociedad paralela que se descompone como un sistema moribundo.

Este relato apocalíptico excede los moldes de la novela negra, y se sirve de elementos propios de la novela gótica, la ciencia-ficción, la fantasía mitológica o la escatología mística. El recurso a estos imaginarios es característico de Javier Calvo, que ciertos críticos situarían dentro de una llamada Generación Afterpop, escritores españoles nacidos después de 1970 con una serie de rasgos comunes (Azancot, 2007). Novela policial muy estilizada, diríase que esta investigación literaria se apoya en la legitimación artística del género, ya no más encasillada como un género "popular" o "de consumo", para enfrentarse a cuestiones marcádamente estéticas. Para ello, al respeto por la tradición novelesca de la Barcelona criminal (Vázquez Montalbán, Mendoza, Casavella, Marsé...), se unen influencias tan dispares como Roberto Bolaño (con sus visiones apocalípticas de la violencia política en América Latina) o J. G. Ballard (con sus paisajes ruinosos que hablan de la decadencia de una civilización).

Esta novela nos presenta la violencia política como un absurdo interminable, y la Transición como un proceso de bloqueo institucional que lleva a la muerte de una transcendencia: el fin del futuro o del sueño del futuro. El indiscutible fracaso de la resistencia armada se presenta como el cierre de una esperanza, y la Transición como el cerrojo que mantiene el actual estancamiento espiritual. El jardín colgante es la metáfora de un mundo en suspensión, sin cúpula celeste ni raíces al suelo, hechizado en su amnesia de presente eterno. 


\subsection{El año en que el futuro acabó (comenzó) \\ (Marcelo Expósito, 2007)}

El vídeo-ensayo El año en que el futuro acabó (comenzó) realizado en 2007 por Marcelo Expósito reflexiona sobre el papel de la imagen en la construcción de los discursos sobre la Transición ${ }^{10}$. La pieza está motivada por la hipótesis de que los relatos instituidos sobre la transición democrática se naturalizan en parte importante gracias a una representación visual cuyas imágenes sobrecodificadas, paradójicamente, 'muestran' cada vez menos e impiden cada vez más la comprensión de los hechos históricos que supuestamente representan ${ }^{11}$. Expósito propone como eje central de su pieza una cuenta atrás visual que presenta aceleradamente una serie de imágenes en retrospectiva, desde las elecciones democráticas de 1977 hasta la Guerra Civil (1936-1939). En cierto modo, el vídeo de Expósito hace literal el dixit benjaminiano de peinar la historia a contrapelo (Benjamin, 2008) con el objetivo de plantear una reflexión crítica sobre la construcción del relato histórico ${ }^{12}$.

El procedimiento de trabajo del artista está condensado en la cita de Heiner Müller que abre la pieza- no creo que la fotografía sea un instrumento de memoria. La memoria es trabajo, no algo que puedas simplemente contemplar. De este modo, todo el posicionamiento crítico de Expósito está vehiculado a través de la manipulación visual de imágenes de archivo, las cuales son sometidas a un fuerte trabajo de montaje, ajustes de velocidad, repeticiones y contrastes. La noción de montaje, como el propio artista ha reconocido en diversas ocasiones, es aquí crucial:

\footnotetext{
${ }^{10}$ Accesible en: < http://dziga.insularo.net/exposito-2007 > . Accesado a 31 abr. 2012.

${ }^{11}$ Texto de presentación de la pieza en <http:/www.hamacaonline.net/obra.php?id=592 >. Accesado a 31 abr. 2012.

${ }^{12}$ La referencia a Benjamin como clave para comprender el trabajo de Expósito va más allá de la simple cita erudita: tanto en su trabajo teórico como artístico, Expósito ha explorado sistemáticamente las tesis estéticas y políticas del pensador alemán (cf. Expósito, 2009-2010).
} 
Para mí, la invención más formidable que la vanguardia artística aporta en el siglo pasado simultáneamente a la cultura y a la política, en el montaje. Me refiero al montaje que (...) no es un ejercicio de estilo que se pliega sobre sí sino que constituye una herramienta para pensar, para pensar críticamente. Montar es, en este sentido, reunir cosas heterogéneas en un conjunto fragmentado que resalta su discontinuidad estructural destruyendo cierta ilusión de autocoherencia y unidad de la forma y del discurso 'sin renunciar por ello a la producción de sentido’ (Expósito, 2006, p. 3).

El gesto fundamental de Expósito en El año en que el futuro acabó (comenzó) es ciertamente simple: invertir el orden cronológico de una serie de imágenes icónicas. En su simpleza, sin embargo, ataca las bases del discurso celebratorio de la Transición. La citada serie de Andrés y Prego - que ya habría sido tempranamente contestada por Expósito en el documental No haber olvidado nada, codirigido junto a Fito Rodríguez y Gabriel Villota en 1996-7 - constituye el ejemplo paradigmático de representación de la Transición como una teleología impecable, donde una afortunada sucesión de causas y efectos desemboca en la constitución de las cortes en 1977, definida como el momento preciso en que los cimientos de la democracia quedan firmemente asentados ${ }^{13}$. Al invertir materialmente este relato y manipular la presentación de sus imágenes más representativas, Expósito subraya las dos ideas fundamentales que ya hemos identificado en los discursos críticos de la Transición: la brutal violencia política que jalonó este proceso y la continuidad indiscutida de los aparatos del estado franquistas.

El relato oficial, naturalizado y asimilado como la explicación coherente de los hechos, es enfrentado por Expósito a una imagen distorsiona-

\footnotetext{
${ }^{13}$ Andrés y Prego: La Transición, capítulo 13, emitido el 15 de octubre de 1995. Accesible en: $<$ http://www.rtve.es/alacarta/videos/television/transicion-capitulo-13/752078/ > . Accesado a $31 \mathrm{abr}$. 2012. Aunque no nos detendremos en ello, el trabajo de María Ruido analizado en el siguiente punto también cita críticamente esta serie documental.
} 
da de sí mismo. Las imágenes de la llegada de los diputados al congreso en junio del 77, por ejemplo, adoptan un sentido totalmente diferente al ser remontadas y sucedidas por secuencias de los hechos de la "semana trágica" de enero del mismo año, donde el asesinato del manifestante pro-amnistía Arturo Ruiz a manos de paramilitares de extrema derecha desencadenó una cruda espiral de violencia política (sólo un día después de los hechos se produjo la muerte de María Luz Nájera a causa de un bote de humo policial en la manifestación de repulsa por el asesinato de Ruiz, el secuestro del general Villaescusa a cargo del GRAPO y el asesinato de cinco abogados laboralistas en Madrid a manos de un comando de extrema derecha; cf. Sánchez Soler, 2010, p. 53-57). El sucesivo encadenamiento de hechos en retrospectiva no deja de acumular, año tras año, nuevas capas de significado al relato convencional de la Transición: Expósito subraya en su montaje la presencia continuada de Juan Carlos de Borbón junto a Franco en calidad de sucesor designado por el propio dictador, la represión del movimiento obrero bajo la dictadura (con referencias a las huelgas de SEAT en el 72-73), los diferentes pactos internacionales del franquismo (desde el reconocimiento del régimen por parte de Estados Unidos en el marco de la Guerra Fría hasta el alineamiento con las fuerzas fascistas del Eje antes de 1945) para desembocar en la Guerra Civil mediante la cual Franco accedió al poder.

La sucesión de imágenes de Expósito plantea claramente que la Transición, lejos de ser un proceso impecable, habría estado estructuralmente marcada por una violencia política incesante y por la absoluta impunidad de los responsables de los crímenes de la dictadura. Esta idea se verá resaltada en la pieza a través de un significativo epílogo visual que, rompiendo con la edición extrema de las imágenes de archivo que articulan la parte central de la pieza, representa, en un tono de documentación aséptica y sin ningún tipo de comentario añadido, la exhumación de una 
fosa común en Uclés (Cuenca) donde yacían los cuerpos de 439 soldados republicanos fusilados por las tropas franquistas. Esta imagen sitúa el discurso crítico de Expósito en el marco de lo que en sus propias palabras fue el terremoto psicosocial del movimiento denominado de recuperación de la memoria histórica (Expósito, 2010). Dicho movimiento social no se limitó a la exhumación de restos de represaliados republicanos sino que consiguió generar un amplio debate público en torno a la importancia de investigar a los responsables de los crímenes franquistas y reparar a sus víctimas_ en términos generales, las bases de este movimiento recibieron con frialdad la aprobación de la Ley de Memoria Histórica aprobada por el primer gobierno de José Luis Rodríguez Zapatero (PSOE) en 2007 al considerarla excesivamente tibia con la depuración legal de responsabilidades de la dictadura. Este movimiento-con el que Expósito se alinea en esta y otras piezas, como su 143.353 (los ojos no quieren estar siempre cerrados) de 2010-impugnó sistemáticamente la estrategia de silenciamiento del pasado dictatorial y represivo del estado español que se impuso en los discursos celebratorios de la Transición, constituyendo, así, uno de los principales vectores para su contestación crítica.

3.4 Lo que no puede ser visto debe ser mostrado

(María Ruido, 2010)

Si el trabajo de Expósito apela al remontaje y la manipulación crítica de las imágenes constitutivas del discurso celebratorio de la Transición, el vídeo-ensayo Lo que no puede ser visto debe ser mostrado realizado por María Ruido en 2010 explora aquellas representaciones visuales que han sido oscurecidas y censuradas en los relatos dominantes sobre este período $^{14}$. En términos generales, la filmografía de Ruido constituye uno

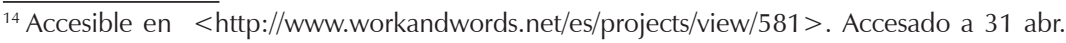
2012.
} 
de los trabajos de reflexión más sólidos en torno a las políticas de la representación en la Transición y la dictadura franquista, con una atención muy particular a los archivos de televisiones públicas del estado español ${ }^{15}$.

En esta pieza, Ruido combina secuencias tomadas de los archivos de los canales públicos Televisión Española y Televisión Gallega con materiales provenientes del cine activista producido en el estado español en los años 70, al cual hemos tenido ocasión de hacer referencia previamente. Ruido concede un papel central al documental militante Rocío, realizado por Fernando Ruiz Vergara en 1980. Esta película, en que Ruiz Vergara se proponía contestar críticamente el folclore y falsos mitos que ha creado la Andalucía oficial (Alvarado, 2010), se formulaba una denuncia explícita de la matanza de trabajadores en Almonte y Río Tinto llevadas a cabo, en los primeros años de la Guerra Civil, por miembros de Falange. La mención explícita del que fuera fundador de la hermandad rociera de Jerez de la Frontera, José María Reales, como responsable de la masacre le valió a Ruiz Vergara una denuncia de sus herederos que se saldó con una pena de arresto, el pago de elevadas indemnizaciones y el secuestro y censura de su película —algo que sucedía por vez primera tras la aprobación de la constitución de 1978. El director andaluz se vio obligado a substituir toda mención a Reales por un rótulo que indicaba Supresión por sentencia de la Sala Segunda del Tribunal Supremo del 3.4.1984'16. Ruido recupera la secuencia en que la película es abruptamente interrumpida por la introducción de este rótulo. La vídeo-artista subraya formalmente este corte mediante un efecto sonoro y la introducción de varios fotogramas en negro con el rótulo CUT, un recurso que será repetido a lo largo de

\footnotetext{
${ }_{15}^{15}$ Pueden destacarse al respecto su proyecto de 2008 Plan Rosebud (presentado en dos partes, La escena del crimen y Convocando a los fantasmas o su más reciente ElectroClass (2011).

${ }^{16}$ Cuando Rocío fue finalmente emitida por las cadenas públicas TVE y Canal Sur en los años 90 este rótulo fue directamente suprimido, por decisión de la distribuidora, sin que quedara ninguna constancia de la censura a la que el documental había sido sometido (Espinosa Maestre; Río Sánchez, 2009, p. 28-29).
} 
la pieza remarcando una idea fundamental: el discurso dominante de la Transición impuso una feroz censura de los relatos más contestatarios con el desarrollo hegemónico del proceso, particularmente en lo referente a los crímenes impunes del franquismo. Como afirmara Luis Vivas Marzal, uno de los miembros del Tribunal Supremo que en 1984 ratificó la condena y censura de Ruiz Vergara:

Es indispensable inhumar y olvidar si se quiere que los sobrevivientes y las generaciones posteriores a la contienda, convivan pacífica, armónica y conciliadamente, no siendo atinado avivar los rescoldos de esa lucha para despertar rencores, odios y resentimientos adormecidos por el paso del tiempo (cit. en Alvarado, 2010).

Ruido lleva mucho más allá esta lógica de "inhumación y olvido" que habría caracterizado el proceso de la Transición al sugerir la tesis de que ciertos sectores antifranquistas-particularmente aquellos vinculados al PCE que, tras su legalización, colaboró activamente con el desarrollo institucional del proceso transicional—colaboraron activamente en el silenciamiento de las voces más críticas de la izquierda. La vídeo-artista recupera fragmentos de la película $\mathrm{O}$ todos o ninguno realizada por el Colectivo de Cine de Clase (Helena Lumbreras y Mariano Lisa) entre 1975 y 1976, la cual prestaba atención a la combativa huelga de Laforsa en 1975, la más larga registrada en España desde el 36, dando voz a las propias bases del movimiento obrero. Según declara el propio Lisa en la película de Ruido, la figura de Lumbreras resultó intolerable para directores como Pere Portabella, más próximos a la órbita institucional del PCE, que activamente promovieron su marginación debido a la doble incomodidad que suponía su condición de mujer y su discurso político radicalizado ${ }^{17}$.

\footnotetext{
${ }^{17}$ La cuestión del sexismo y la misoginia de ciertos sectores antifranquistas es igualmente referida en la película de Ruido mediante la cita de la película Margarita y el lobo de Cecilia Bartolomé (1969) y la entrevista a la directora.
} 
En su esfuerzo por visibilizar los discursos críticos oscurecidos por los relatos celebratorios de la Transición, Ruido no pierde de vista la reactivación contemporánea del debate en torno a este período. Puede entenderse, en este sentido, su introducción de toda una serie de imágenes que remiten a la llamada ley de Amnistía aprobada en 1977. La promulgación de esta ley, que amnistiaba los actos de intencionalidad política cometidos antes de diciembre de 1976, había sido largamente reclamada por la izquierda y los antiguos sectores antifranquistas cuya movilización en estos años fue contestada con una sistemática violencia estatal y para-estatal (véase la mención a la semana trágica del 77 en el punto anterior). Con el trasfondo de unas palabras de Jorge Luis Marzo en torno a la dificultad de reapropiarse de la memoria del franquismo tras la supuesta "amnesia" de los 80, Ruido construye una secuencia de imágenes ciertamente significativa: partiendo del consejo de ministros presidido por el rey en que se aprobó el precedente directo de la ley de Amnistía (el Real Decreto de amnistía parcial del 76), Ruido intercala imágenes de la movilización social pro-amnistía y su represión violenta por parte de grupos ultraderechistas en la segunda mitad de los 70 con secuencias que subrayan la presencia de Juan Carlos de Borbón como sucesor designado por el propio Franco. Este juego de imágenes, del que se puede extraer la ya mencionada crítica en torno a la continuidad del aparato de estado franquista en el sistema democrático, cobra un sentido adicional en el año de realización de la película de Ruido. Si bien la aprobación de la ley de Amnistía fue reclamada y celebrada en su día por los sectores vinculados a la resistencia antifranquista, lo cierto es que en torno a 2010 esta ley supuso el principal argumento jurídico para detener los intentos de investigación de los crímenes del franquismo movilizados por el ya referido movimiento de recuperación de la memoria histórica.

La película de Ruido se cierra, de hecho, subrayando este renovado valor político que la reflexión crítica sobre la Transición parece haber 
adoptado para la comprensión de la realidad contemporánea del estado español. Ruido introduce un extracto en que un trabajador se dirige a las cámaras de la televisión pública gallega denunciando la manipulación informativa de este medio en la cobertura informativa del desastre ecológico del Prestige ${ }^{18}$. El modo en que sus palabras de este ciudadano-quien termina preguntando si sus declaraciones serán publicadas—son interrumpidas por Ruido-mediante el ya referido recurso al corte introducido en la cita de Ruiz Vergara-parece señalar críticamente que el silenciamiento de voces contestatarias previamente referido en el período de la Transición probablemente habría continuado ejerciendo sus mecanismos en el desarrollo posterior de la democracia parlamentaria española.

\section{Conclusiones}

Como afirmamos al inicio, el diálogo transdisciplinar se muestra especialmente fértil a la hora de elucidar debates complejos e inacabados, en los que la imbricación entre la lógica de los hechos y la lógica de lo ficcional enreda las relaciones y oscurece la discusión. En ese contexto, el estudio sociológico de las prácticas estéticas se revela una práctica pertinente de cara al auto-conocimiento social. Considerando que la realidad abordada se acerca a temas tan espinosos como las prácticas de violencia extrema, las herramientas de representación de este universo cobran especial relevancia.

Respecto al debate actual sobre la Transición española, creemos haber iluminado dos posiciones extremas (la visión celebratoria y la visión

\footnotetext{
${ }^{18} \mathrm{Es}$ importante señalar que la respuesta gubernamental ante el hundimiento de este petrolero en 2002 generó un movimiento de contestación en que algunos autores identifican el inicio de un ciclo de movilizaciones sociales heterogéneas que, en conjunto, habrían estado motivadas por un profundo descrédito y desafección respecto al modelo sociopolítico de la Transición (Fernández-Savater, 2011).
} 
crítica) que, si bien no tendrían la profundidad de un estudio retrospectivo, son especialmente útiles como categorías analíticas para comprender el debate en curso. Para la construcción de esta tipología, el recurso a la observación de las prácticas estéticas es especialmente valioso.

En definitiva, queda en abierto toda una serie de desarrollos posibles que iría, desde el estudio genealógico de estas dos categorías, hasta la relación estructural de cada una de ellas con una posición socio-política en el presente (donde una memoria del pasado correspondería a una visión del presente y a un proyecto de futuro). Todas estas cuestiones permanecen como preguntas formuladas al aire, a la espera de una investigación que dé cuenta de sus múltiples desdoblamientos.

Pablo La Parra Pérez. Estudiante de Doctorado del Departamiento de Lenguas y Literaturas Española y Portuguesa de la Universidad de Nueva York.

$\sum$ pablo.laparra@nyu.edu

Julio Souto Salom. Estudiante de magister en sociología en la Universidad Federal de Rio Grande do Sul (UFRGS). Licenciado en Sociología - Universitat Valencia (2011); licenciado en Ciencia Política - Universitat Valencia (2011).

$>$ juliosouto2103@gmail.com

\section{Referencias}

AZANCOT, N. La generación Nocilla y el afterpop piden paso. En: El Mundo - El Cultural, 19/07/2007. Disponible en <http://www.elcultural.es/version_papel/LETRAS/21006/La_generacion_Nocilla_y_el_afterpop_piden_paso/>. Acceso a 30 abr. 2013.

ALVARADO, A. Maldita Rocío: la película más prohibida, la que algunos quisieran ignorar. Blogs \& Docs, Barcelona, dic. 2010. Disponible en: <http://www.blogsandocs.com/? $p=640>$. Acceso: 30/04/2013)

BALIBREA, M. P. La novela negra en la transición española como fenómeno cultural: una interpretación. Iberoamericana, Barcelona, ii, n. 7, p. 111-118, 2002. Disponible en: <http://www.iai.spk-berlin.de/fileadmin/dokumentenbibliothek/ iberoamericana/07-balibrea.pdf>. Acceso a 30 abr. 2013. 
BENJAMIN, W. Sobre el concepto de Historia. In: Obras, Libro I, vol. 2, Madrid: Abada, 2008.

BERZOSA CAMACHO, A. Cine, activismo y movimientos sociales de una España en transición. Brumaria, [Barcelona], n-24 (Arte y Transición), p. 133-151, 2011.

BERZOSA CAMACHO, A. Cámara en mano contra el franquismo: desde Cataluña a Europa, 1968-1982. La Plata: Al Margen, 2009.

CALVO, J. El jardín colgante. Barcelona: Seix Barral, 2012.

CERCAS, J. Anatomía de un instante. Madrid: Mondadori, 2009.

COLMEIRO, J. F. La novela policíaca española: teoría e historia crítica. Barcelona: Anthropos, 1994.

DUVA, J. Nueve mil presos, a la calle de una tacada. EL PAís, Madrid, 27 dic. 1994. Disponible en <http://elpais.com/diario/1994/12/27/espana/788482818_850215.html>.

EDITORIAL: La foto de un consenso. EL PAÍS, Madrid, 26 jul. 2012. Disponible en: <http://elpais.com/elpais/2012/07/25/opinion/1343238945_430070.html>. Acceso en: 30 abr. 2013.

EDITORIAL: La urgencia de pactar. EL PAÍS, Madrid, 29 jul. 2012. Disponible en: <http://elpais.com/elpais/2012/07/28/opinion/1343500958_001790.html>. Acceso en: 30 abr. 2013.

EDITORIAL: Pactos de Estado. EL PAÍS, Madrid, 12 abr. 2012. Disponible en: < http://elpais.com/elpais/2012/04/11/opinion/1334169962_320274.html> ACceso: 30 abr. 2013.

EGEA, J. El desencanto. La mirada del padre y las lecturas de la transición. Symposium, [S.I.], no 58.2, p. 79-92.

ESPINOSA MAESTRE, F.; DEL RÍO SÁNCHEZ, Á. Fascismo y Transición: 'Rocío' y Fernando Ruiz. Cuadernos para el diálogo, [S.I.], no 42, p. 20-29, junio 2009.

ESCOLAR, I. Otra democracia. Eldiario.es. El fin de la España de la Transición. Madrid, Marzo 2013. Disponible en: <http://www.eldiario.es/escolar/democracia_6_113448657.html>. Acceso en: 31 marzo 2013.

EXPÓSITO, M. Entrar y salir de la institución: autovalorización y montaje en el arte contemporáneo. Tranversal. European Institute for Progressive Cultural Policies, octubre 2006. Disponible en: <http://eipcp.net/transversal/0407/exposito/es>. Acceso en: 30 abr. 2013.

EXPÓSITO, M. Walter Benjamin, productivista. (Monografía final de doctorado). Buenos Aires: Universidad de Buenos Aires, 2009-2010. Disponible en: < http://marceloexposito.net/pdf/exposito_doctorado1gruner.pdf>. Acceso en: 30 abr. 2013. 
EXPÓSITO, M. 143.353 (los ojos no quieren estar siempre cerrados. en VVAA: Principio Potosí. Madrid: Museo Nacional Centro de Arte Reina Sofía, 2010. Disponible en: <http://marceloexposito.net/pdf/exposito_143353.pdf >. Acceso en: 30 abr. 2013.

FERNÁNDEZ-SAVATER, A. El arte de esfumarse. Crisis e implosión de la cultura consensual en España. El Estado Mental, nô1, pp. 5-11, 2011.

GARCÍA-MERÁS, L. El cine de la disidencia. La producción militante antifranquista (1967-1981) In: CARRILLO, Jesús (ed.). Desacuerdos 4. Sobre arte, políticas y esfera pública en el estado español. Barcelona, Donostia y Sevilla: MACBA, Arteleku y UNIA, 2007.

GUBERN, Román, ed. Historia del cine español, Madrid: Cátedra, 1995.

HURTADO MARTÍNEZ, M. C. La inseguridad ciudadana de la transición a una sociedad democrática, España (1977-1989). (Tésis Doctoral). Cuenca: Ediciones de la Universidad de Castilla-La Mancha, 1999.

IBÁÑEZ, J. A Contracorriente. Madrid: Fundamentos, 1997.

LLERA, F. J. Gran Coalición. El País, Madrid, 4 de junio 2012. Disponible en: < http://elpais.com/elpais/2012/05/30/opinion/1338404663_242896.html>. Acceso en: 30 abr. 2013.

MARAÑÓN, G.; TOHARIA, J. J. De la angustia cívica al pacto político. El País, Madrid, 13 mayo 2012. Disponible en: < http://elpais.com/elpais/2012/05/09/ opinion/1336586021_294364.htm>. Acceso en: 30 abr. 2013.

MARTíN, A.; QuíleZ, C. Piel de Policía. Madrid: Diario Público - Colección Novela Negra, 2011. 2 vols.

MARTÍNEZ, G. CT o 35 años de cultura española. Descripción, estupor, temblores y un ejemplo barcelonés de cómo fue desactivada la cultura en la Transición. Brumaria,[Barcelona], n.24 (Arte y Transición), p. 43-55, 2011.

MEDINA DOMÍNGUEZ, A. Exorcismos de la memoria. Políticas y poéticas de la melancolía en la Espala de la transición, Madrid: Ediciones Libertarias, 2001.

MITCHELL, W. What Do Pictures Want? The Lives and Loves of Images, Chicago: Chicago University Press, 2005.

MONTERDE, E. Veinte años de cine español. Barcelona: Paidós, 1993.

MOREIRAS MENOR, C. Cultura herida. Literatura y cine en la España democrática. Madrid: Ediciones Libertarias, 2002.

PALACIO, M. Marcos interpretativos, Transición democrática y cine. Un prólogo y tres consideraciones. In: PALACIO, Manuel. (ed.) El cine y la transición política en España (1975-1982). Madrid: Editorial Biblioteca Nueva, 2011. p. 19-30. 
POLLOCK, G. Modernidad líquida y análisis transdisciplinar de la cultura. In: BAUMAN, Zygmunt et al.: Arte ilíquido?, Madrid: Sequitur, 2007. p. 27-34.

RANCIÈRE, J. S'il faut en conclure que l'histoire est fiction. Des modes de la fiction. In: Le Partage du sensible. Esthétique et politique. París: La fabrique, 2000. RANCIÈRE, Jacques. The Method of Equality: An Answer to Some Questions. In: ROCKHILL, Gabriel \& WATTS, Philip: Jacques Rancière. History, Politics, Aesthetics, Durham y Londres: Duke University Press, 2009.

ROMAGUERA i RAMIÓ, J.; SOLER DE LOS MÁRTIRES, L. Historia crítica y documentada del cine independiente en España 1955-1975. Barcelona: Laertes, 2006.

ROSE, J. The Man who Mistook his Wife for a Hat or A Wife is Like an Umbrella. Fantasies of the Modern and Postmodern. In: ROSS, A. (ed.). Universal Abandon? The Politics of Postmodernism. Minneapolis: Universtiy of Minnesota, 1988. p. 237-250.

SANTOS, B. S. Un discurso sobre las ciencias. In: Una epistemología del Sur. La reinvención del conocimiento y la emancipación social. México: Siglo XXI CLACSO, 2009. p. 17-59.

SÁNCHEZ FERLOSIO, R. La cultura, ese invento del Gobierno. EL PAíS, Madrid, 22 nov. 1984. Disponible en: <http://elpais.com/diario/1984/11/22/opinion/469926007_850215.html>. Acceso en: 31 marzo 2013.

SÁNCHEZ SOLER, Mariano. La transición sangrienta: una historia sangrienta del proceso democrático en España 1975-1983. Madrid: Ediciones Península, 2010.

SEVILLA, J.; PIQUÉ, J. Juntos, mejor. El País, Madrid, 6 junio 2012. Disponible en: <http://elpais.com/elpais/2012/06/04/opinion/1338836756_046267.html> Acceso en: 30 abr. 2013.

TAVARES DOS SANTOS, J. V. Violências e conflitualidades. Porto Alegre: Tomo Editorial, 2009.

TAVARES DOS SANTOS, J. V. Violências e dilemas do controle social nas sociedades da modernidade tardia. São Paulo em Perspectiva, São Paulo, v. 18, n. 1, mar. 2004. Disponible en: <http://www.scielo.br/scielo.php?script=sci arttext $\&$ pid $=$ S0102-88392004000100002\&lng $=$ en $\& n r m=$ iso $>$. Acceso en: $3 \overline{1}$ abr. 2013.

VALLES CALATRAVA, J. R. La novela criminal española en la transición. En: Boletín del Instituto de Estudios Almerienses. Letras. n. 8, p. 227-240, 1988. Disponible en: <http://dialnet.unirioja.es/descarga/articulo/81763.pdf>. Acceso en: 30 abr. 2013.

VILARÓS, Teresa. El mono del desencanto. Una crítica cultural de la transición española (1973-1993). Madrid: Siglo XXI, 1998. 
Filmografía

AHUMADA, J.R.: Gais al carrer, 1977.

ANDRÉS, E.; PREGO, V. La Transición (serie de 13 capítulos), Televisión Española, 1996.

BARTOLOMÉ, C. Margarita y el lobo, 1969.

COLECTIVO DE CINE DE CLASE. O todos o ninguno, 1975-1976.

COLECTIVO DE CINE DE MADRID. Vitoria, 1976.

COOPERATIVA DE CINEMA ALTERNATIU. Can Serra: la objeción de conciencia en España, 1976.

COOPERATIVA DE CINEMA ALTERNATIU. La Dona, 1976.

EXPÓSITO, M.; RODRÍGUEZ, F.; VILLOTA, G. No haber olvidado nada, 19961997.

EXPÓSITO, M. 143.353 (los ojos no quieren estar siempre cerrados), 2010.

EXPÓSITO, M. El año en que el futuro acabó (comenzó), 2007.

QUER, S. El día más difícil del rey (mini-serie de 2 capítulos), Televisión Española/Televisió de Catalunya, 2010.

RUIDO, M. Plan Rosebud ("La escena del crimen y "Convocando a los fantasmas"), 2008.

RUIDO, M. ElectroClass, 2011.

RUIDO, M. Lo que no puede ser visto debe ser mostrado, 2010.

RUIZ VERGARA, F. Rocío, 1980.

VÍDEO-NOU. Història urbanística, 1978.

Recebido em: 06/05/2013

Aceite final: 07/06/2013 